\title{
Implementasi Pelayanan Administrasi Kependudukan Desa Kalimanah Wetan Purbalingga Berbasis Online
}

\author{
Dheska Ranita Setyowati", Anton**, Ummu Radiyah*** \\ *,**,*** STMIK Nusa Mandiri Jakarta \\ *dheska.ranita@gmail.com, ${ }^{* *}$ anton@nusamandiri.ac.id, ${ }^{* * *}$ ummu.urd@nusamandiri.ac.id
}

\begin{abstract}
Implementation of Population Administration Services in the Village of Kalimanah Wetan Purbalingga is still done manually. In the processing of data population is still conventional with a data collection system that is now felt there are still many shortcomings that occur, because the existing system still uses sheets of paper so that it can cause existing data easily lost or damaged. The system development in the form of a web-based Population Service system in Kalimanah Wetan Village is a system that provides information on population data and web- based letter printing services, so as to help speed and quality in delivering information and simplify correspondence printing services to be more effective and efficient. In this system, the web can only be accessed by users, namely citizens and administrators. The method used in developing this system is SDLC (System Development Life Cycle) with the waterfall process model. In this study, besides describing the theoretical study that is used as the basis of the preparation, it will also be discussed regarding system design and the making of Population Services web. So that it is expected to be implemented in a product that will correct any shortcomings in the old system.
\end{abstract}

Keyword: Keywords: Website, Population service system, Administration

\section{Pendahuluan}

Seiring dengan perkembangan teknologi informasi yang berkembang sangat pesat apalagi diiringi dengan makin maraknya internet di kalangan masyarakat. Kebutuhan akan informasi yang cepat dan tepat sangatlah diperlukan oleh suatu instansi, organisasi maupun perusahaan. Kemajuan teknologi inilah yang mengharuskan instansi mengikuti perkembangan teknologi dan terus meningkatkan kemampuannya dalam mengelola datadata dan informasi. Menurut Asyifa Hayat, dkk [1] suatu instansi pemerintahan membutuhkan suatu sistem informasi yang mendukung kebutuhan instansi pemerintah dalam menciptakan efisiensi dan efektifitas kerja dalam pengelolaan data penduduk.

Sistem pelayanan pembuatan surat-surat yang berjalan pada Kantor Desa Kalimanah Wetan Kabupaten Purbalingga bersifat konvensional dan pengolahan data penduduk masih manual. Dalam arti penduduk harus datang langsung ke kantor kepala desa untuk mengajukan surat permohonan kemudian penduduk akan mengisi formulir, penduduk membawa serta syarat-syarat yang dibutuhkan, petugas menerima kembali formulir dan mengecek kelengkapan syarat-syaratnya dan setelah itu selanjutnya dibuatkan surat permohonan sehingga menjadi tidak efisien dari segi waktu dan tenaga dalam mengelola data penduduk dan memproses pembuatan surat-surat karena dalam rangkaian proses tersebut masih menggunakan sistem manual [2] begitupun dalam menyebarluaskan pengumuman-pengumuman penting untuk warga desa masih menggunakan media surat yang dicetak atau kertas yang diedarkan dari rumah ke rumah.

Informasi yang dapat diakses melalui internet yaitu situs atau website, contohnya web tentang pelayanan penduduk di desa. Pada aktifitas pelayanan kependudukan, warga diharuskan mengurus surat permohonan yang diinginkan pada kantor desa atau kelurahan dengan mengikuti sejumlah prosedur yang berlaku sehingga dalam pembuatan surat-surat tertentu memakan waktu dan tenaga yang cukup lama. Pelayanan tersebut perlu dilakukan dengan cepat dan tepat untuk mendapatkan suatu informasi, tetapi pada kenyataannya pengelolaan data pada kelurahan atau desa masih dilakukan dalam bentuk pembukuan atau arsip-arsip, sehingga seringkali terjadi kesalahan bahkan arsip data yang hilang atau rusak karena terlalu banyak arsip yang ada [3].

Pada penelitian yang telah dilakukan oleh Paryanta, Sutariyani, dan Susilowati (2017), dengan memanfaatkan teknologi informasi, pemerintah desa bisa berinteraksi dan bertukar informasi dengan warga, sehingga mampu memperlancar jalannya pemerintah desa di dalam memberikan pelayanan dan informasi kepada masyarakat [4]. Imaniawan dan Wati (2017) mengemukakan bahwa tidak hanya untuk menunjang mobilitas warga juga memudahkan desa untuk mensosialisasikan program-program desa, pelayanan masyarakat serta pengolahan data agar masyarakat dapat lebih cepat mendapatkan informasi yang dibutuhkan serta mendapat pelayanan cetak surat-menyurat secara efektif dan efisien [5]. Seiring dengan program pemerintah tersebut, adanya web khusus di desa-desa semakin dibutuhkan. 
Dengan latar belakang permasalahan tersebut, mendorong penulis untuk menyusun penelitian guna membantu memberi solusi terhadap permasalahan yang ada. Untuk selanjutnya dalam penyusunan penelitian ini penulis menyajikan "Sistem Infomasi Pelayanan Administrasi Kependudukan Desa Kalimanah Wetan Purbalingga Berbasis Web".

\section{Metode Penelitian}

Analisis sistem pelayanan pembuatan surat yang berjalan pada Kantor Desa Kalimanah Wetan Purbalingga bersifat konvensional dan pengolahan data penduduk desa tersebut masih manual. Dalam arti penduduk datang langsung ke kantor kepala desa untuk mengajukan surat permohonan. Penduduk mengajukan surat permohonan yang dibutuhkan dengan membawa berkas persyaratan yang dibutuhkan dan diserahkan ke petugas. Petugas atau staf pemerintahan memeriksa berkas persyaratan dan memberikan formulir kepada penduduk. Penduduk mengisi formulir kemudian diserahkan kembali ke petugas. Petugas memeriksa formulir yang diisi oleh penduduk dan membuat surat permohonan yang dibutuhkan oleh penduduk. Kepala desa menandatangani surat yang telah dibuat oleh petugas dan menyerahkan surat tersebut ke bagian sekretaris desa. Sekretaris desa membuat laporan data kependudukan dan menyerahkan surat ke penduduk yang bermohon. Activity diagram proses sistem yang berjalan di Kantor Desa Kalimanah Wetan ditunjukkan pada Gambar 1.

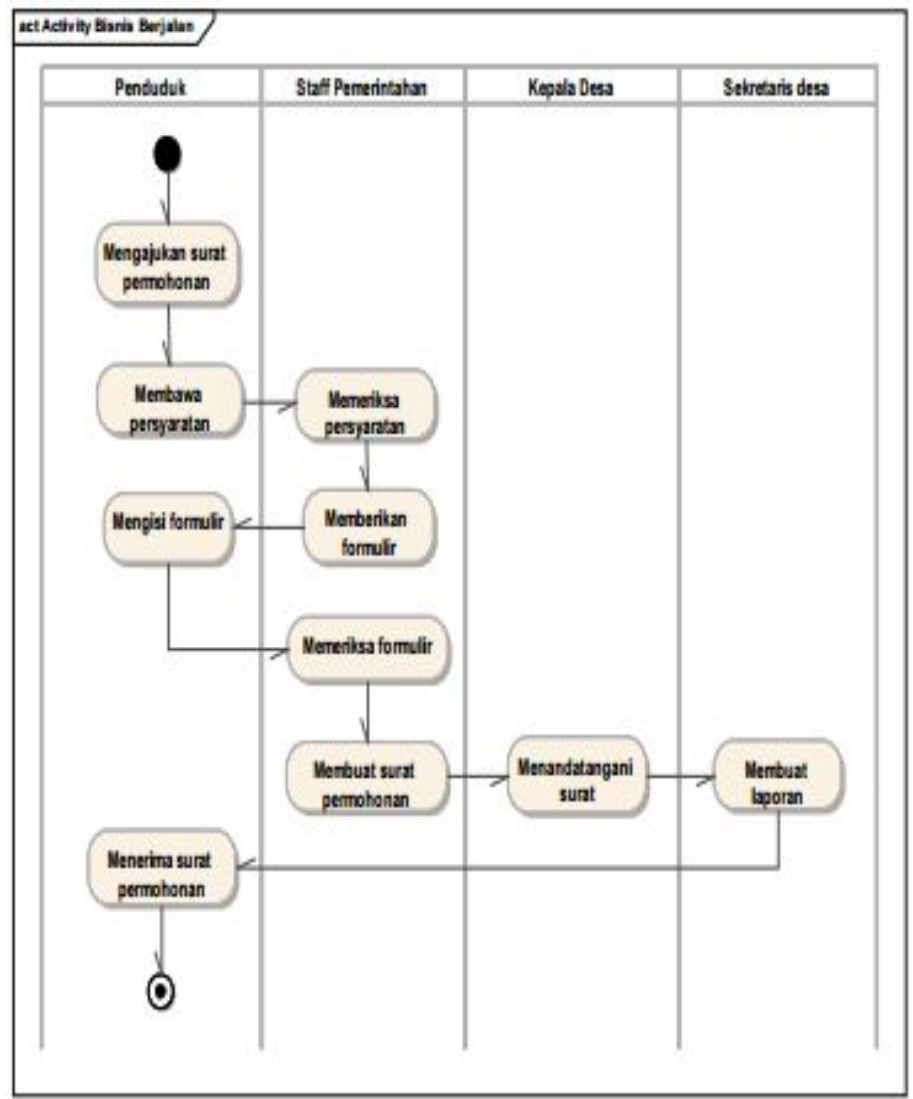

Gambar 1. Activity diagram proses sistem berjalan

Ada beberapa teknik pengumpulan data yang dilakukan pada penelitian untuk merancang sistem dan program usulan pada Kantor Desa Kalimanah Wetan ini adalah sebagai berikut:

1. Observasi

Analisis awal dilakukan pengamatan secara langsung kegiatan pelaksanaan pelayanan administrasi masyarakat di Kantor Kepala Desa Kalimanah Wetan Purbalingga untuk mendapatkan data-data yang diperlukan dan mengetahui proses sistem yang berjalan. Data demografi penduduk Desa Kalimanah Wetan serta data contoh surat-surat dikumpulkan sebagai sampel. Semua prosedur ini telah disetujui oleh kepala Desa.

2. Wawancara

Penulis melakukan wawancara langsung kepada Kepala Desa Kalimanah Wetan dan staf administrasi mengenai data-data yang berhubungan dengan pelayanan administrasi kependudukan. Selain itu penulis 
juga mengajukan beberapa pertanyaan yang berkaitan dengan permasalahan yang berkaitan dengan pelayanan administrasi masyarakat.

3. Studi Pustaka

Penulis mencari informasi dan pengetahuan tambahan yang bekaitan dengan pokok pembahasan pada penulisan penelitian, melalui buku-buku atau ebook, artikel, jurnal, literatur dan media online untuk mendukung penyusunan penelitian ini.

\subsection{Metode Pengembangan Perangkat Lunak}

Metode yang digunakan dalam melakukan pengembangan sistem aplikasi yaitu SDLC (System Development Life Cycle) model waterfall. Model waterfall ini menyediakan pendekatan alur hidup perangkat lunak secara sekuensial atau terurut dimulai dari analisa, desain, pengkodean, pengujian dan tahap pendukung (support). Berikut adalah alur dari model waterfall yaitu:

1. Analisa Kebutuhan Software

Kebutuhan software pada tahap ini dianalisa menjadi dua yaitu user dan admin. Kebutuhan user meliputi permintaan pelayanan surat menyurat masyarakat, serta mendapatkan informasi mengenai Desa Kalimanah Wetan sedangkan admin meliputi mengedit, menghapus dan menambah data maupun informasi yang ada dalam sistem pelayanan kependudukan Desa Kalimanah.

2. Desain

Desain perangkat lunak termasuk desain basis data, struktur navigasi dan rancangan antar muka. Desain database digambarkan dalam bentuk LRS (Logical Relational Struture) dan ERD (Entity Relational Diagram). Tahap ini mentranslasi kebutuhan perangkat lunak dari tahap analisis kebutuhan ke representasi desain agar dapat diimplementasikan menjadi program pada tahap selanjutnya. Desain perangkat lunak yang dihasilkan pada tahap ini juga perlu didokumentasikan.

\section{Code Generation}

Desain harus ditranslasi ke dalam program perangkat lunak. Hasil dari tahap ini adalah program komputer sesuai dengan desain yang telah dibuat pada tahap desain. Pada tahap ini dilakukan penerjemahan penulisan kode-kode dengan menggunakan bahasa pemrograman terstuktur yaitu bahasa pemrogaman HTML, PHP, JavaScript, Apache, CSS (Cascading style sheet), menggunakan Software Dreamweaver CS6 dan XAMPP, dan database menggunakan MySQL dan PhpMyAdmin.

\section{Testing}

Pengujian fokus pada perangkat lunak dari segi logik, fungsional dan memastikan semua bagian sudah diuji. Hal ini dilakukan untuk meminimalisir kesalahan (error) dan memastikan keluaran yang dihasilkan sesuai dengan yang diinginkan. Pada tahap ini pengujiannya menggunakan black box testing.

\section{Support}

Agar sebuah website dapat diakses melalui internet, maka diperlukan sebuah domain dan hosting. Domain dan hosting adalah dua layanan yang berbeda dan memiliki fungsi yang berbeda pula. Dalam tahap pendukung atau pemeliharaan dapat mengulang proses pengembangan mulai dari analisis spesifikasi untuk perubahan perangkat lunak yang sudah ada, tapi tidak untuk membuat perangkat lunak baru. Untuk mendukung dan memelihara dengan melakukan pembaruan isi website dan membackup data secara berkala.

\subsection{Ruang Lingkup}

Ruang lingkup sistem adalah penulis membuat tampilan web untuk user dan administrator. Petugas dalam hal ini berperan sebagai administrator yang berwenang untuk mengelola website, mulai dari menambah, mengubah dan menghapus data-data di halaman khusus administrator (data Admin, pelayanan publik dan pengaturan web). User yang dimaksud adalah pengunjung dan penduduk Desa Kalimanah Wetan. Pengunjung dalam hal ini dapat melihat informasi secara umum yang ada di website, seperti artikel, album kegiatan, potensi desa dan profil desa, selain itu pengunjung dapat mengisi menggunakan chatbox untuk tanggapan masyarakat dan melihat lokasi desa. Sedangkan penduduk Desa Kalimanah Wetan dapat melihat data diri dan mengurus administrasi kependudukan dalam hal mencetak surat (Surat Keterangan Usaha, Surat Tidak Mampu, Surat Keterangan, Surat Pengantar, Surat Pengantar SKCK, Surat Keterangan Pindah). Dalam tampilan pelayanan publik penduduk Desa Kalimanah Wetan dapat input formulir surat sesuai data diri. Setelah data diproses, sistem akan menghasilkan output berupa surat yang bisa langsung dicetak atau disimpan. 


\section{Hasil dan Pembahasan}

Tampilan website telah dirancang sebagai media interaksi dengan pengguna. Di bawah ini beberapa tampilan website sesuai dengan dekomposisi fungsi sistem usulan.

1. Tampilan Halaman Admin

a. Halaman Login Admin

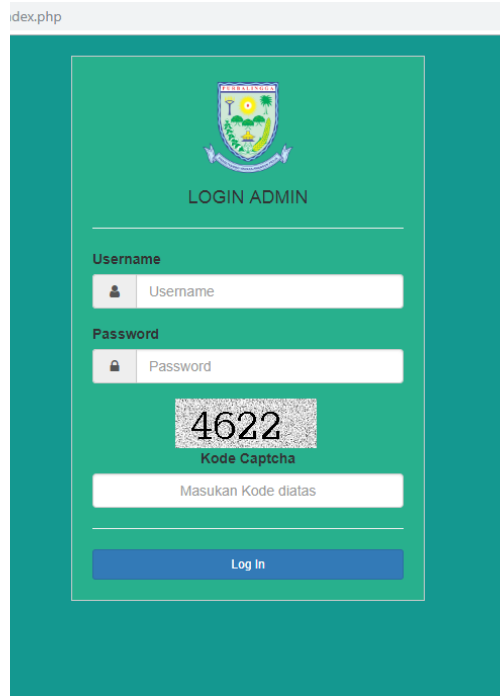

Gambar 2. Tampilan Halaman Login Admin

Pegawai atau staf Desa Kalimanah Wetan dalam hal ini berperan sebagai administrator yang berwenang untuk mengelola website, mulai dari menambah, mengubah dan menghapus data-data di halaman khusus administrator (data Admin, pelayanan publik dan pengaturan web). Pegawai dapat melakukan login melalui user interface atau tampilan seperti pada Gambar 2 dan setelah itu bisa terlihat halaman yang dikelola seperti halaman data admin, pelayanan publik dan pengaturan web. Pelayanan publik seperti daftar data penduduk, data manajemen surat dan profil desa.

b. Halaman Menu Manajemen Surat

Admin mengelola data-data admin, data-data penduduk dan sekaligus data untuk pelayanan publik seperti manajemen surat, manajemen pengelolaan web seperti manajemen profil desa, isi berita, pengumumanpengumuman, album galery desa, identitas desa dan identitas web. Halaman tampilan menu manajemen surat ditampilkan pada Gambar 3.

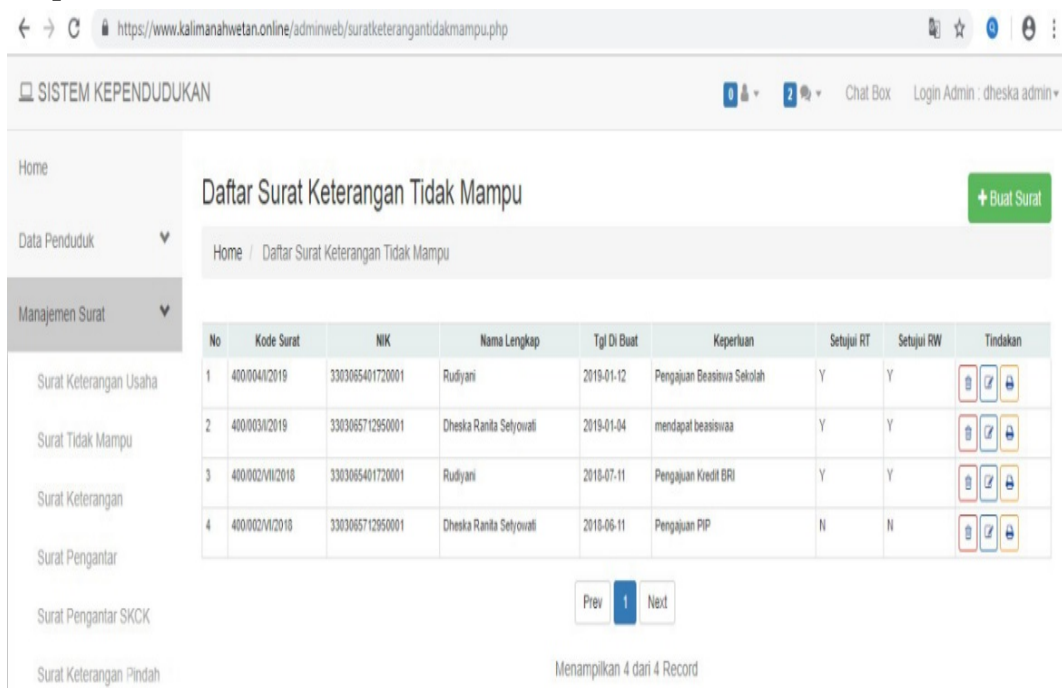

Gambar 3. Tampilan Halaman Menu Manajemen Surat 
c. Halaman Menu Buat Surat

Pada Menu Manajemen Surat terdapat beberapa jenis surat yang disediakan atau yang bisa diajukan yaitu Surat keterangan tidak mampu, Surat keterangan usaha, surat pengantar pembuatan SKCK, surat keterangan pindah. Penduduk memasukkan Nomor Induk Kependudukan atau NIK kemudian jenis keperluan seperti yang digambarkan pada Gambar 4. Selanjutnya untuk diproses oleh staf Desa Kalimanah Wetan dan diteruskan kepada Ketua RT dan RW untuk disetujui.

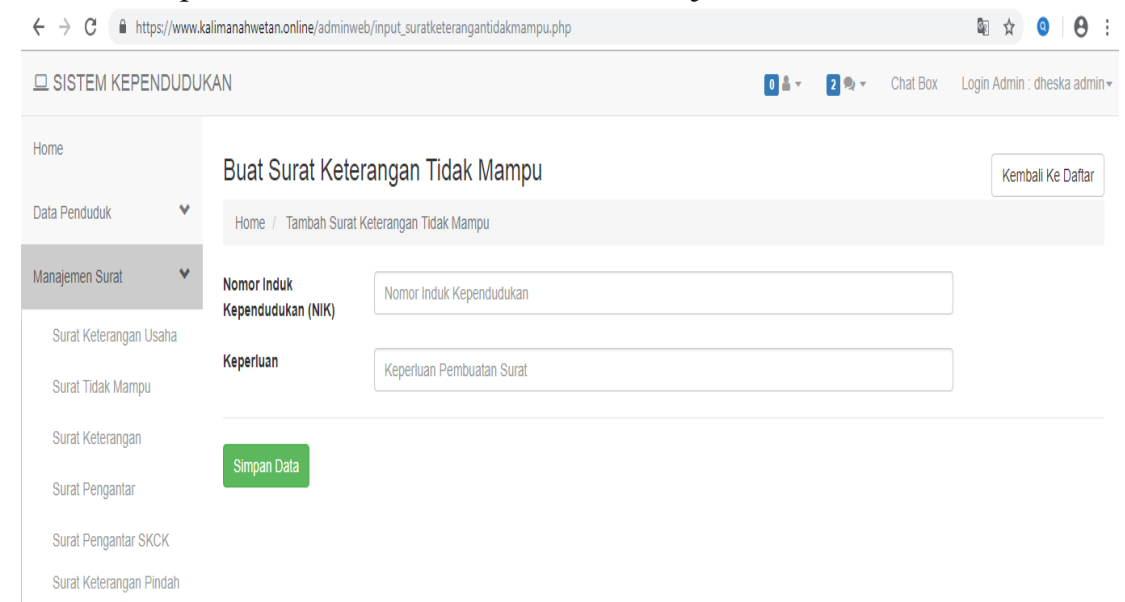

Gambar 4. Tampilan Halaman Menu Buat Surat

d. Halaman Tampilan Cetak Surat

Penduduk yang mengajukan permohonan pembuatan surat selanjutnya diproses oleh staf desa dan diteruskan ke ketua RT maupun RW untuk disetujui, setelah surat disetujui oleh RT maupun RW, surat telah bisa dicetak. Penduduk dapat mengakses halaman cetak surat seperti pada tampilan pada Gambar 5.

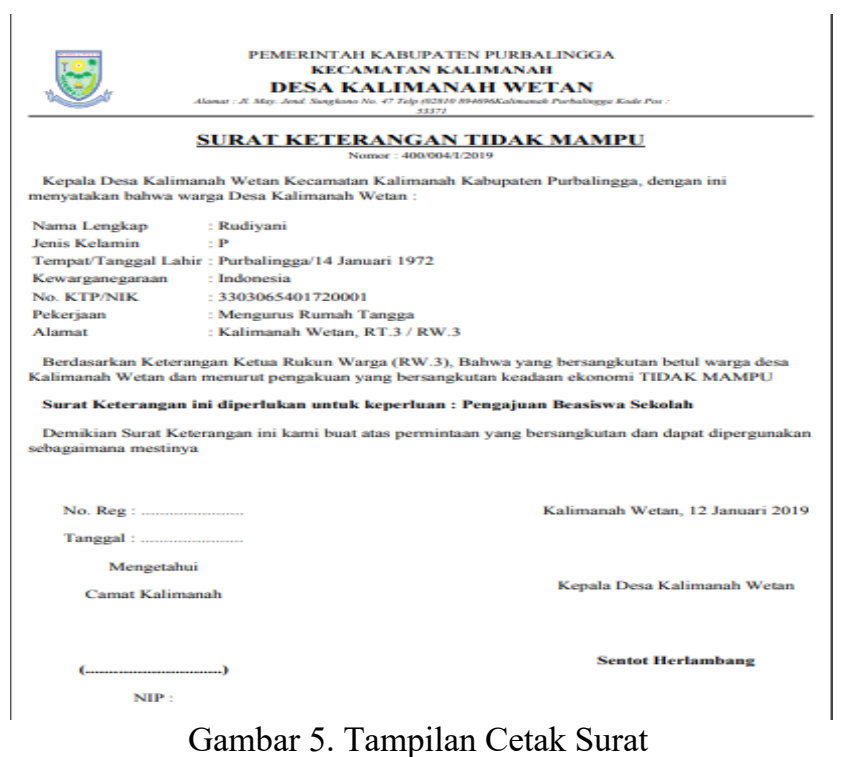

2. Tampilan Halaman Beranda Pengunjung

Selain admin, terdapat user biasa yaitu user pengunjung. Pengunjung dalam hal ini adalah penduduk Desa Kalimanah Wetan atau pengunjung lain yang ingin mengetahui profil Desa Kalimanah Wetan. Tampilan beranda untuk pengunjung ditampilkan secara detail pada Gambar 6. Pada Menu tersebut ditampilkan halaman utama Website Desa Kalimanah Wetan, isinya menampilkan beberapa berita disertai gambar, peta lokasi Desa, link atau tautan untuk obrolan atau tanggapan masyarakat. Pada menu ini juga menjadi akses untuk masuk dan 
melihat ke menu artikel, album kegiatan, potensi desa dan profil desa. Akses untuk mengisi form untuk keperluan permohonan surat-surat keterangan disiapkan tautan ke ruang penduduk
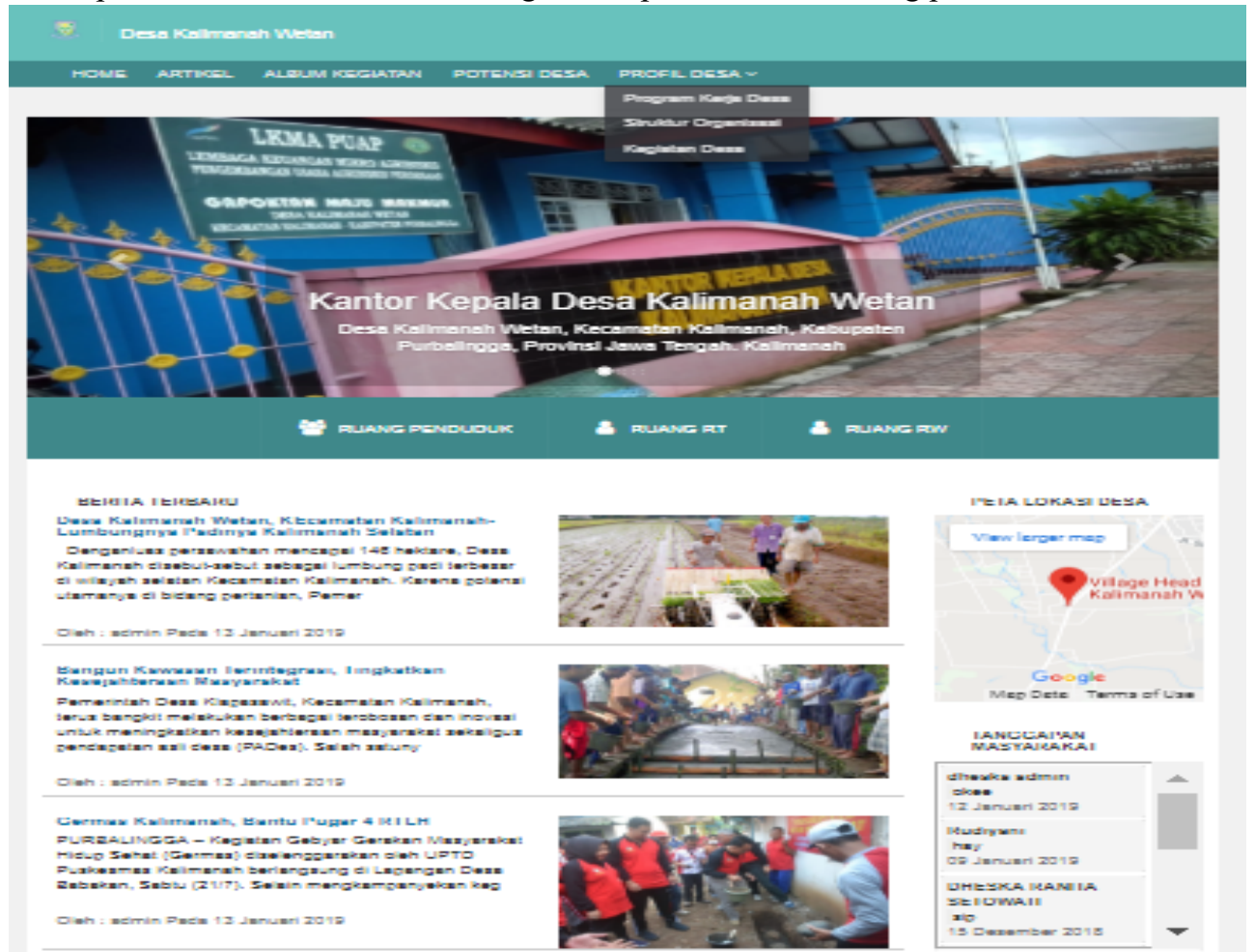

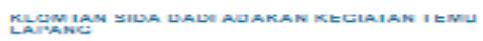

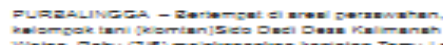
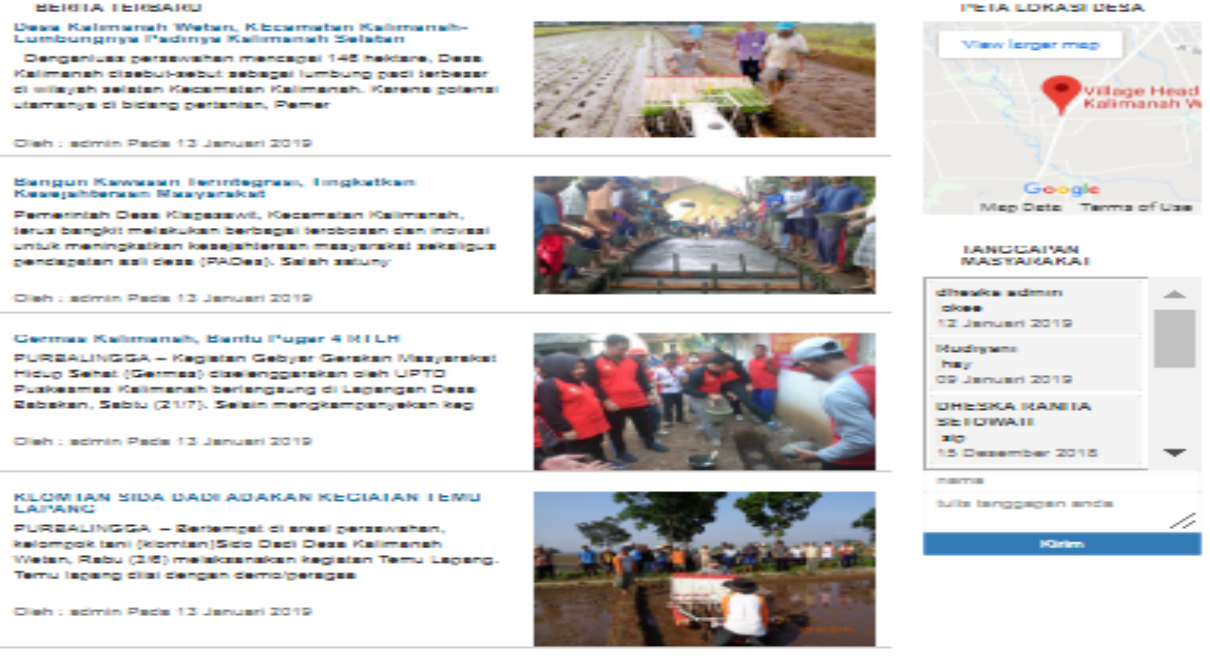

Mancinalny,

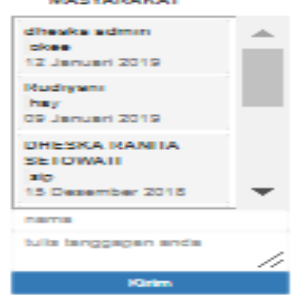

3. Form Login Penduduk

Gambar 6. Tampilan Halaman Beranda Pengunjung

Pada Tabel 1 dan 2 merupakan hasil dari pengujian sistem dari beberapa form penting dalam website ini. Terlihat fungsi dalam setiap form telah sesuai dengan rancangan dan berjalan sesuai dengan yang diharapkan. Tabel 1. Hasil Pengujian Blackbox Testing login penduduk

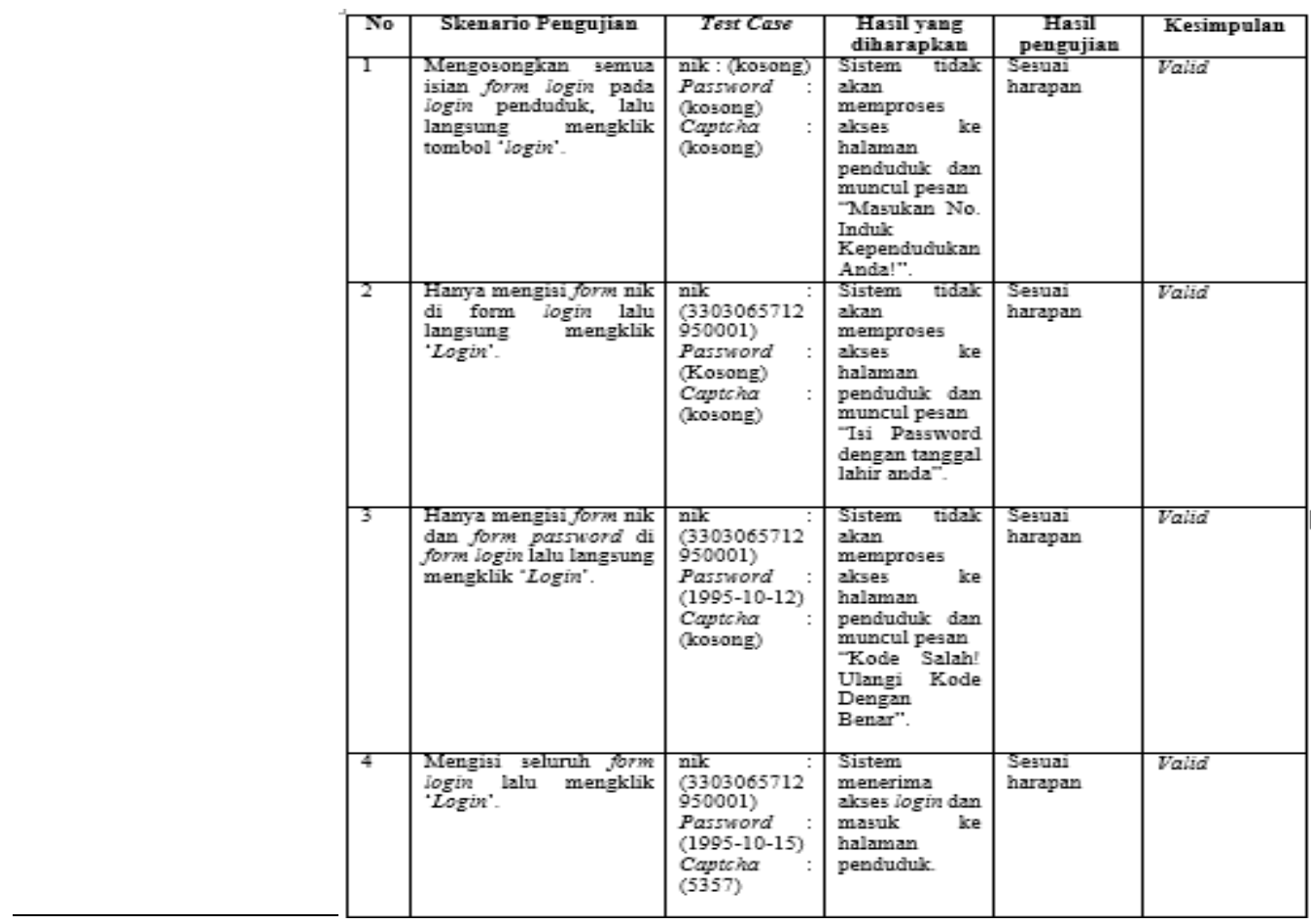


4. Form Pengisian Surat

Tabel 2. Hasil Pengujian Blackbox Testing Pengisian surat

\begin{tabular}{|c|c|c|c|c|c|}
\hline No & Skenario Pengujian & Test Case & $\begin{array}{l}\text { Hanil yeng } \\
\text { diksrapksun }\end{array}$ & $\begin{array}{c}\text { Hasil } \\
\text { peuguji } \\
\text { an }\end{array}$ & Kesimpular \\
\hline 1 & $\begin{array}{l}\text { Momgosougkall } \\
\text { semuz isian form } \\
\text { pangisian surzt, lalu } \\
\text { lamgrung mongoklik } \\
\text { tombol 'Simpan Data' }\end{array}$ & $\begin{array}{l}\text { Keperlugn : } \\
\text { (kcosong) } \\
\text { Keterangan } \\
\text { lain : (kosong) } \\
\text { Masa berlaku: } \\
\text { (kosong) }\end{array}$ & $\begin{array}{l}\text { Sistom bdak } \\
\text { alkan } \\
\text { memproses } \\
\text { cotak surat } \\
\text { dan akan } \\
\text { muncul } \\
\text { pesan } \\
\text { "Masukan } \\
\text { ksparluan } \\
\text { surat!". }\end{array}$ & $\begin{array}{l}\text { Soruai } \\
\text { barapm }\end{array}$ & Tolía \\
\hline 2 & 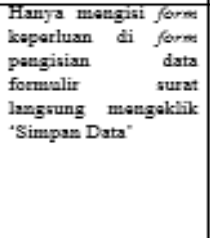 & $\begin{array}{l}\text { Jenis Surat } \\
\text { Keperluan: } \\
\text { (beasiswa) } \\
\text { Keperluan lain } \\
\text { ( (kosong) } \\
\text { Nasa berlaku: } \\
\text { (cosong) }\end{array}$ & 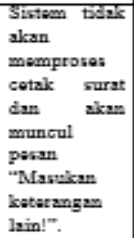 & $\begin{array}{l}\text { Sosuai } \\
\text { barapm }\end{array}$ & Tolid \\
\hline 3 & 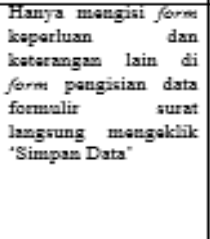 & $\begin{array}{l}\text { Jenis Surat } \\
\text { Keperluan: } \\
\text { (beasiswa) } \\
\text { Keperluan lain } \\
\text { : (dokumen } \\
\text { pendukang) } \\
\text { Masa berlaku: } \\
\text { (kcosong) }\end{array}$ & 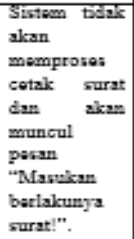 & $\begin{array}{l}\text { Sosuai } \\
\text { harapm }\end{array}$ & Folia \\
\hline 4 & $\begin{array}{l}\text { Momgisi soluruh form } \\
\text { pengisian surat lalu } \\
\text { menglis 'Simpan } \\
\text { Data". }\end{array}$ & $\begin{array}{l}\text { Jenis Swat } \\
\text { Keperluan: } \\
\text { (beasiswa) } \\
\text { Keperluan lain } \\
\text { : (dokumen } \\
\text { pendukung) } \\
\text { Masa berlaku: } \\
\text { (5 hari) }\end{array}$ & $\begin{array}{l}\text { Sistem alkan } \\
\text { memproses } \\
\text { cotal surat } \\
\text { dun aken } \\
\text { muncul } \\
\text { pesan "Data } \\
\text { surat borhasil } \\
\text { dibuat". }\end{array}$ & $\begin{array}{l}\text { Sosuai } \\
\text { harapm }\end{array}$ & Falid \\
\hline
\end{tabular}




\section{Kesimpulan dan Saran}

\subsection{Kesimpulan}

Kesimpulan pokok dari penelitian ini yaitu Website Pelayanan Administrasi Penduduk Desa Kalimanah Wetan telah diimplementasikan dan dapat memudahkan dalam memberikan pelayanan dan informasi kepada masyarakat secara lebih cepat, laporan kependudukan lebih mudah dan efisien karena data-data yang diperlukan dalam proses peyimpanan dengan database dan terdapat fasilitas cetak surat pengantar dan surat keterangan bagi warga Desa Kalimanah Wetan, Purbalingga. Sistem ini dapat mengelola data warga sehingga setiap pengelolaan surat selalu terhubung pada database warga sehingga surat yang dikeluarkan sesuai dengan data warga di kelurahan dan format surat telah diatur oleh sistem sehingga terbantu dalam pengarsipan yang tertata dengan baik. Sistem ini juga telah memudahkan petugas desa untuk mensosialisasikan program-program desa sehingga lebih efektif dan efisien dalam pelayanan, dan memudahkan warga dalam mendapat informasi seputar kegiatan dan kejadian di desa Kalimanah Wetan.

\subsection{Saran}

Dalam sistem ini disadari masih banyak kekurangan dan kelemahan, oleh karena itu untuk pengembangan selanjutnya disarankan penambahan dan pengembangan fitur sistem seiring dengan kebutuhan dan perkembangan sistem ke depannya. Sistem diimplementasikan dalam ruang lingkup yang lebih luas lagi, yaitu pada tingkat kecamatan guna mendukung pemerintah dalam melihat pertumbuhan penduduk dan perkembangan kegiatan warga yang menyangkut administrasi kependudukan serta sistem ini juga dapat dikembangkan menjadi sistem berbasis android, dimana akan lebih memudahkan penduduk dalam melakukan pembuatan surat dan mendapatkan informasi secara lebih cepat.

\section{Daftar Pustaka}

[1] Asyifa hayat, E., Retnadi, E., \& Gunadhi, E. Perancangan Sistem Informasi Kependudukan Berbasis Web, 2014. 11(23027339), 39-45. https://doi.org/10.1016/B978-1-59749-995-8.00005-3

[2] Fujiyati, O., Sukadi. Sistem Informasi Pengolahan Data Kependudukan Desa Purwoasri. 2015. Vol.7 No.1, Page 1-8. https://ijns.org/journal/index.php/speed/article/view/1303.

[3] Triana, Yunita. Analisa dan Perancangan Sistem Informasi Administrasi Kependudukan Berbasis Dekstop. Studi Kasus: Kantor Kelurahan Parit Lalang. 2015. https://repository.atmaluhur.ac.id/handle/123456789/709

[4] Paryanta, Sutariyani, \& Susilowati, D. 2017. Sistem Informasi Administrasi Kependudukan Berbasis Web Desa Sawahan. IJSE - Indonesian Journal on Software Engineering, 2017. 3(2), 77-81. Retrieved from https://ejournal.bsi.ac.id/ejurnal/index.php/ijse/article/download/2980/1929

[5] Imaniawan, F. F. D., \& Wati, F. F.. Sistem Informasi Administrasi Kependudukan Berbasis Web Pada Desa Bogangin Sumpiuh. Indonesian Journal on Networking and Security - Volume 7 No 3 - 2017, 7(3), 1-9. https://doi.org/10.1207/S15327809JLS1004new 